\title{
Influence of Temperature on Sticking Behavior of Iron Powder in Fluidized Bed
}

\author{
Jian-Hua SHAO, Zhan-Cheng GUO and Hui-Qing TANG \\ State Key Laboratory of Advanced Metallurgy, University of Science and Technology Beijing, 100083 Beijing, China. \\ E-mail: jhshao2004@163.com, zcguo@metall.ustb.edu.cn, hqtang@ustb.edu.cn
}

(Received on December 27, 2010; accepted on March 30, 2011)

\begin{abstract}
The influence that temperature has on bed pressure drop, grain size and morphology of iron fines in a hot-state visualizable fluidized bed was investigated in this work. It was found that there are both a start sticking temperature $\left(T_{\mathrm{s}}, 673 \mathrm{~K}-773 \mathrm{~K}\right)$ and a critical defluidization temperature $\left(T_{\mathrm{c}}, 923 \mathrm{~K}-973 \mathrm{~K}\right)$ of the iron particles in the fluidized bed. Not only the bed pressure drop but the agglomeration degree of the iron particles shows a strong dependence on temperature. It is also confirmed experimentally that the crystallized iron fines without whisker show a certain viscosity even at a temperature far from the melting point.
\end{abstract}

KEY WORDS: fluidized bed; iron powder; sticking; defluidization; pressure drop.

\section{Introduction}

The fluidized bed reduction technology of iron ore fines, which does not rely on the coking and sintering processes, is recently focused as a prereduction unit of smelting reduction processes for refraining from increasingly scarce raw materials and meeting more demanding environmental standards. ${ }^{1,2)}$ However, the most serious bottleneck obstacles of industrial utilization of a fluidized bed reduction is the problem of defluidization, ${ }^{3-5}$ ) making continuous operation impossible, which results from sticking among individual ore particles.

Recently most individuals seem to agree that the unintentional agglomeration of iron ore fines has some features to occur mostly during metallization of ore. ${ }^{6,7)}$ The first type of sticking appears when some ore particles coat with the fibrous iron on the grain surface. This kind of sticking is initiated by the contact of the needles that hook mechanically the grains together and appears at temperatures above 873 $\mathrm{K} .{ }^{7,8)}$ The second type of sticking is caused by higher quantity of fresh precipitated iron. This iron has got a high activity and due to this tendency it leads to a build-up of small surfaces. If the quantity of freshly precipitated iron is too big it leads to sticking. Between iron ore parts appears high adhesion energy and that carries out to agglomeration. ${ }^{9-11)}$ Moreover, Studies by Fang ${ }^{12)}$ indicated that most of iron ore fines have a critical temperature of defluidization, over which defluidization happens, otherwise not appears. Therefore, temperature and new produced iron were considered to be important factors of sticking of iron ore fines reduced in fluidized bed.

However, we know little about the detailed impact and mechanism of grains sticking. In present work, we investigated the influence that temperature has on sticking behavior of iron powder in fluidized bed with a view to better understand the sticking mechanism of reduction iron ore fines in fluidized bed.

\section{Experimental}

\subsection{Experimental Setup}

The main experimental facility is a flow-visualization fluidized bed, of which the schematic diagram is shown in Fig. 1. The reactor is made of double transparent quartz tubes, the inner diameter of which separately are $30 \mathrm{~mm}$ and 70 $\mathrm{mm}$, and the inner tube is fluidized bed. Gas firstly flows through the interlayer between the outer tube and the inner tube to be preheated, and then it flows into fluidized bed.

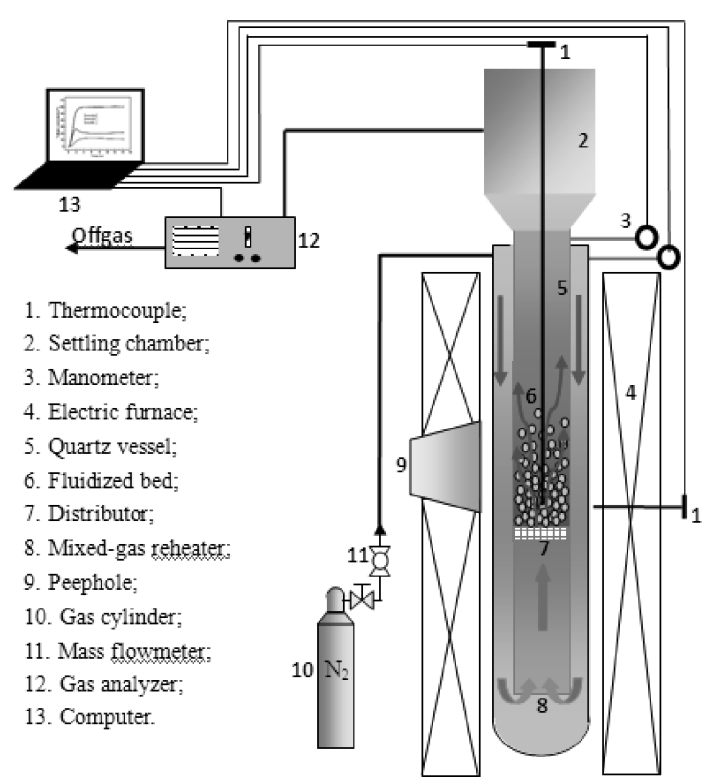

Fig. 1. Schematic diagram of visualization fluidized bed. 
The resistance furnace has a narrow window to observe fluidization state on line. Specimen temperature in fluidization bed is obtained by the thermocouple insetting bed from the top of the reactor and is controlled by the thermocouple of the resistance furnace.

The fluidization tests were carried out with $70 \mathrm{~g}$ of analytical pure iron powders (TFe $>98 \%$, grain size: $38-75$ $\mu \mathrm{m}$, from Sinopharm Chemical Reagent Co., Ltd.). The sample in the reactor was protected by high purity nitrogen all the time. The nitrogen gas supply rate was $0.5 \mathrm{~L} \cdot \mathrm{min}^{-1}$ before heated up to operation temperature and after fluidization test. At operation temperature the gas superficial velocity was set to $0.20 \mathrm{~m} \cdot \mathrm{s}^{-1}$ at the atmospheric pressure. The pressure drop of fluidized bed was monitored by two pressure sensors. The morphological characterization of the sample was performed using a JSM6480LVscanning electron microscope (SEM).

Moreover, in order to observe whether iron particles has phase change or crystal transition between room temperature and $1073 \mathrm{~K}$, differential thermal analyses (DTA) were conducted with a LINSEIS STA PT1600 instrument at a heating rate of $3 \mathrm{~K} \cdot \mathrm{min}^{-1}$ from room temperature to $1073 \mathrm{~K}$. The mass of iron powder samples was almost $0.025 \mathrm{~g}$, which were protected by injection of inert high purity nitrogen with a flow rate of $0.03 \mathrm{~L} \cdot \mathrm{min}^{-1}$.

\subsection{Statistic Analysis of Particles Diameter after Fluid- ization}

Feret diameter is used to get an average value of particle size by using microscopic measurements. ${ }^{5)}$ This is done by taking the value sizing up the distance between two tangents on opposite sides of the particle profile, and the tangents are parallel to some fixed direction. By measuring many fixed directions of particles, and after taking the mean and standard deviation we have a useful metric. Note that the particles are randomly scattered on the microscope slide. There is no preferred orientation.

Feret diameter of sample particles after fluidized test were measured according to their optical micrographs (the particle number was greater than 600), and then cumulative distribution of particle size and the fitting cumulative distribution functions $U\left(D_{\mathrm{p}}\right)_{T}$ were obtained. Setting $50 \%$ and $84.13 \%$ for $U\left(D_{\mathrm{p}}\right)_{T}$ respectively, $D_{50}$ and $D_{84.13}$ at some specific temperatures were figured out. According to those values of $D_{50}$ and $D_{84.13}$, the function equations of $D_{50}$ and $D_{84.13}$ and temperature, $D_{50}(T)$ and $D_{84.13}(T)$ were gained by exponential curve fitting these data. After that, put them into the Eq. (1), ${ }^{13)}$ the relationship between the logarithmic normal distribution functions of granularity and temperature was obtained.

$$
f\left(D_{\mathrm{P}}\right)=\frac{1}{\sqrt{2 \pi} \lg \frac{D_{84.13}}{D_{50}}} \exp \left[-\frac{\left(\lg D_{\mathrm{P}}-\lg D_{50}\right)^{2}}{2 \lg ^{2} \frac{D_{84.13}}{D_{50}}}\right]
$$

At the same time, the average diameters $D_{\mathrm{nL}}$ at different temperatures can be counted by the formula $(2)^{13)}$.

$$
D_{n L}=\frac{\sum n_{i} d_{i}}{\sum n_{i}}
$$

Based on those values of $D_{\mathrm{nL}}$, the function equations of $D_{\mathrm{nL}}$ and temperature, $D_{\mathrm{nL}}(T)$ are gained by fitting them.

\section{Results and Discussion}

\subsection{Pressure Drop of Fluidized Bed}

The pressure drop of the fluidized bed with iron powder contained at different temperatures is given in Fig. 2. The pressure drop at $298 \mathrm{~K}$ almost kept constant during the whole test time, but at other temperatures, they have different degree of reduction. At $673 \mathrm{~K}, 773 \mathrm{~K}$ and $873 \mathrm{~K}$, the pressure drop decreased evenly. At $923 \mathrm{~K}$, the pressure drop was gradually reducing within $35 \mathrm{~min}$. However, it was almost constant after that. Moreover, at higher temperatures of $973 \mathrm{~K}$ and $1023 \mathrm{~K}$, the fluidized bed just maintain fluidization less than ten minutes and the pressure drop decreased obviously, and then the pressure drop had fall sharply at defluidization moment. After that, the pressure drop remained constant at a lower level.

The derivative of the bed pressure drop with respect to time at different temperatures (as mentioned in Fig. 2) was evaluated by linear regression, and the results are given in Fig. 3. At $298 \mathrm{~K}, 673 \mathrm{~K}, 773 \mathrm{~K}$ and $873 \mathrm{~K}$, the fitting time

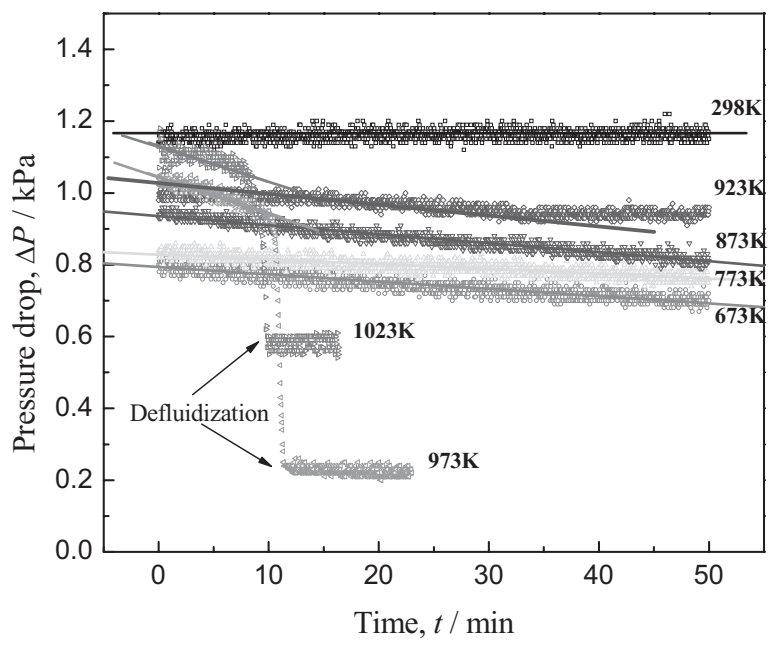

Fig. 2. Variation of pressure drop of fluidized bed with time of fluidization at different temperatures.

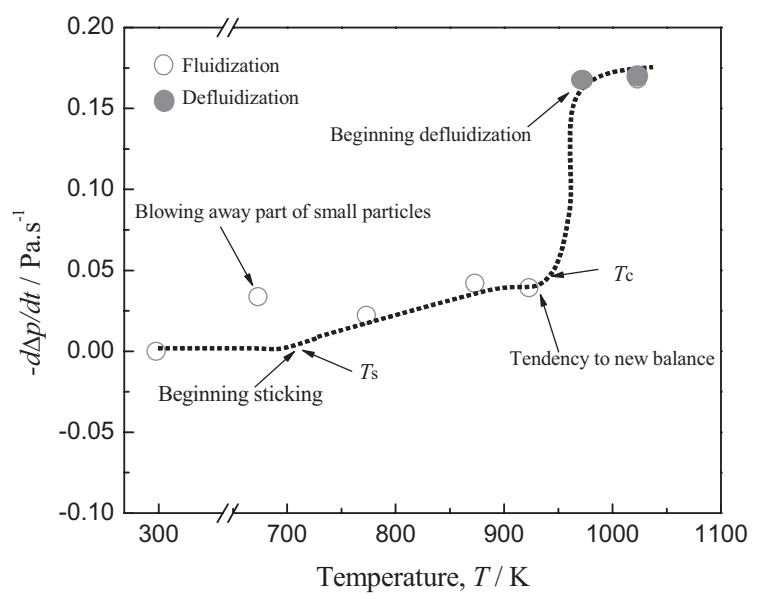

Fig. 3. Relationship between pressure drop change rate of fluidized bed during fluidization and temperature. 
was $50 \mathrm{~min}$. At $923 \mathrm{~K}$, it was $35 \mathrm{~min}$. For $973 \mathrm{~K}$ and 1023 $\mathrm{K}$, the fitting time was their respective fluidization time, 10.5 $\mathrm{min}$ and $9 \mathrm{~min}$. The variation rate of the bed pressure drop over time at different temperatures, $\left(\frac{-d \Delta p}{d t}\right)_{T}$, can be obtained by the slope of each line. The results are shown in Fig. 3.

It can be seen from Fig. 3 that the variation rate of the bed pressure drop at $298 \mathrm{~K},\left(\frac{-d \Delta p}{d t}\right)_{298 \mathrm{~K}}$, is about zero, which suggests that iron powder in the bed can maintain a stable fluidization at this temperature. At $673 \mathrm{~K}$, the variation rate of the pressure drop increases obviously. Since then, with the temperature increasing to $923 \mathrm{~K}$, it also increases gradually. However, above $923 \mathrm{~K}$, it increases rapidly.

Moreover, small particles (less than $50 \mu \mathrm{m}$ ) were found in the settling chamber of the fluidized bed at different temperatures. Especially, the maximum appeared at $673 \mathrm{~K}$. As the particle size of the iron powder is inhomogeneous, small particles must exist in iron powder sample. Although gas velocity is constant at this temperature, gas viscosity becomes greater than that at room temperature. Consequently, the drag force of gas increased. When the gravities of part of small particles were smaller than the drag force of gas, they escaped to the settling chamber. Therefore, the main reason of the variation rate of the pressure drop obvious increase was the more thinning bed for small particles leaving. At above $773 \mathrm{~K}$, the amount of small particles in the settling chamber decreased. This showed that small particles impact on the variation rate of the pressure drop decreased.

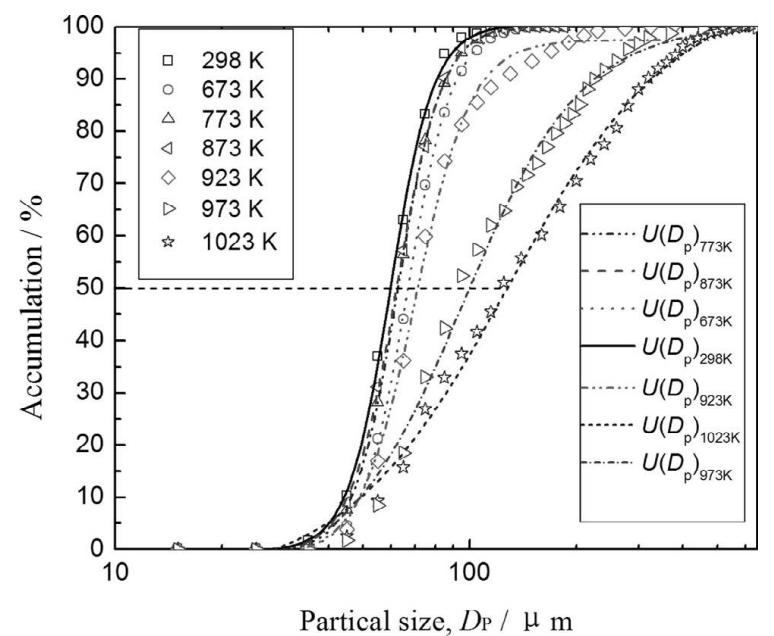

Fig. 4. Cumulativedistribution of grains size at different temperatures.

\subsection{Particle Size of Iron Powder}

The results of cumulative distributions of grain size of the iron powder at different fluidization temperatures are shown in Fig. 4. The fitting functions are listed in Table. 1. As shown in Table 1, the fitting degrees of these cumulative distribution functions are above 0.99 , which suggest these functions are reliable.

Figure 5 shows the calculating results of $D_{\mathrm{nL}}$ and $D_{50}$ based on fitting function as shown in Table 1. It is found that the grain size increases slowly below $873 \mathrm{~K}$, while it rises sharply above $923 \mathrm{~K}$. Therefore it was considered that the transition temperature is near $923 \mathrm{~K}$ for grain size of the iron powder to begin to increase rapidly.

Equations (3)-(5) are applied for calculating $D_{50}, D_{84.13}$ and $D_{\mathrm{nL}}$ at these temperatures. It is found that their degrees of fitting are credible as well.

$$
\begin{aligned}
& D_{50}(T)=60.17+3.46 \times 10^{-5} \exp \left(\frac{T}{70.56}\right), R^{2}=0.96334 \\
& D_{84.13}(T)=63.11+208 \times 10^{-5} \exp \left(\frac{T}{89.35}\right), R^{2}=0.9416 \\
& D_{n L}(T)=63.86+10.53 \times 10^{-5} \exp \left(\frac{T}{76.02}\right), R^{2}=0.97627
\end{aligned}
$$

Values of $D_{50}(T)$ and $D_{84.13}(T)$ were taken into the expression (1), resulting in the logarithmic normal distribution

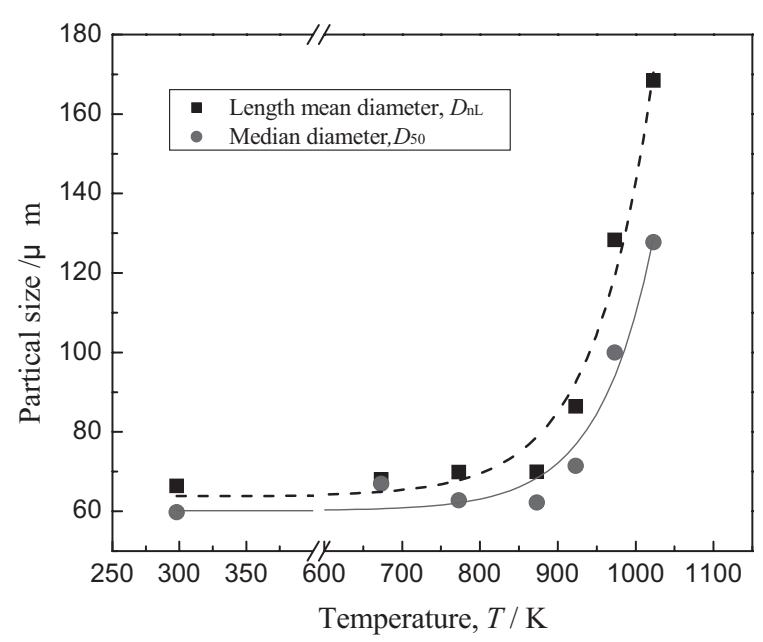

Fig. 5. Relationship between average grain diameter and median diameter of grains and temperature.

Table 1. Fitting functions of cumulative distribution of grains size at different temperatures.

\begin{tabular}{ccc}
\hline Temperature & Cumulative Distribution Function of the Number of Particles & Degree of Fitting $/ R^{2}$ \\
\hline $298 \mathrm{~K}$ & $U\left(D_{\mathrm{p}}\right)_{298} \mathrm{~K}=100.36+(-0.40390-100.36) /\left[1+\left(D_{\mathrm{p}} / 59.798\right)^{7.2094}\right]$ & 0.99951 \\
$673 \mathrm{~K}$ & $U\left(D_{\mathrm{p}}\right)_{673 \mathrm{~K}}=100.15+(-0.56643-100.15) /\left[1+\left(D_{\mathrm{p}} / 66.866\right)^{6.8875}\right]$ & 0.99983 \\
$773 \mathrm{~K}$ & $U\left(D_{\mathrm{p}}\right)_{773 \mathrm{~K}}=100.14+(-0.43143-100.14) /\left[1+\left(D_{\mathrm{p}} / 2.715\right)^{7.1246}\right]$ & 0.99995 \\
$873 \mathrm{~K}$ & $U\left(D_{\mathrm{p}}\right)_{873 \mathrm{~K}}=100.39+(-0.35794-100.39) /\left[1+\left(D_{\mathrm{p}} / 62.206\right)^{6.7961}\right]$ & 0.99983 \\
$923 \mathrm{~K}$ & $U\left(D_{\mathrm{p}}\right)_{923 \mathrm{~K}}=97.505+(-1.5170-97.505) /\left[1+\left(D_{\mathrm{p}} / 70.393\right)^{5.5770}\right]$ & 0.99716 \\
$973 \mathrm{~K}$ & $U\left(D_{\mathrm{p}}\right)_{973 \mathrm{~K}}=100.42+(-5.5863-100.42) /\left[1+\left(D_{\mathrm{p}} / 96.310\right)^{2.6151}\right]$ & 0.99354 \\
$1023 \mathrm{~K}$ & $U\left(D_{\mathrm{p}}\right)_{1023 \mathrm{~K}}=107.17+(-6.3544-107.17) /\left[1+\left(D_{\mathrm{p}} / 128.76\right)^{1.8577}\right]$ & 0.99661 \\
\hline
\end{tabular}


function $f\left(D_{\mathrm{P}}, T\right)$ of iron powder in the fluidized bed at different temperatures. Figure 6 illustrates the influence of temperature on logarithmic normal distribution and diameter of grains. The results suggest that the distribution of bigger diameter particles increases with increasing temperature.

\subsection{Microstructure of the Samples}

The microstructure of the iron powder samples after fluidized test at different temperatures is shown in Fig. 7. The iron particles were mostly independent with each other and few sticking as shown in Fig. 7(a) (at room temperature) and Fig. 7(b) (at $673 \mathrm{~K}$ ). The particle size became uniform and the amount of small particle (less than $50 \mu \mathrm{m}$ ) decreased in Fig. 7(b), compared with that in Fig. 7(a). However, in Fig. 7 (c) (at $773 \mathrm{~K}$ ) and Fig. 7 (d) (at $873 \mathrm{~K}$ ), there are two or three particles sticking together, which shows the iron particles began to take on a certain viscosity.

Moreover, the agglomeration of many particles occurs as shown in Fig. 7(e) (at $923 \mathrm{~K}$ ). Secondary particles formed by multiple grains were coexistent with some original particles. However, at the temperature of $973 \mathrm{~K}$ and $1073 \mathrm{~K}$, subtotal particles participated in the agglomeration and conduced to sticking grains size for growing up rapidly, as shown in Figs. 7(f)-7(h).

\subsection{Sticking Behavior of the Iron Powder}

At temperatures from 298 to $673 \mathrm{~K}$, with increasing temperature, many small particles were flown out of fluidized bed as iron particles had no stickness and the drag force of gas was increasing. Consequently, the rate of pressure drop variation had a relatively large increase at $673 \mathrm{~K}$. It can be imagined that if the particles were epigranular but not normal distribution, the structure of fluidized bed should not vary and the pressure drop should be stable. Therefore, the rate of pressure drop variation at $673 \mathrm{~K}$ should be zero as that at room temperature, as dotted line shown in Fig. 3.

When temperature is closed to $773 \mathrm{~K}$, some small particles (less than $50 \mu \mathrm{m}$ ) adhered to others but not being blown away from bed, so iron grains began to have certain stickiness. Hence the start sticking temperature of iron powder, $T_{\mathrm{s}}$ is about between $673 \mathrm{~K}$ and $773 \mathrm{~K}$ as shown in Fig. 3.

At the temperature from 773 to $923 \mathrm{~K}$, with the viscosity of iron particles increasing gradually, the amount of particles agglomeration increased gradually. Therefore, the particle diameter after fluidization was progressively larger. At about $923 \mathrm{~K}$, the surface viscosity of particles reached a certain level. At the same time, sticking and scattering existed simultaneously, and they could reach a dynamic equilibrium under the function of dissociation forces such as the gravity and the drag force which were caused by fluidizing agent etc. As a result, the pressure drop in the later period of fluidizing became constant as shown in Fig. 2 (923 K).

However, when the temperature was higher, the equilibrium would be destroyed in short order and the initial particles were agglomerated together totally, and then the particle size increased rapidly to form secondary particles. Just as shown in Figs. 7(f)-7(h), these secondary particles also were sticking with each other and became bigger cluster of grains. Moreover, defluidization appeared in a short time. So this equilibrium temperature can be called the critical temperature of defluidization, $T_{\mathrm{c}}$. This temperature in

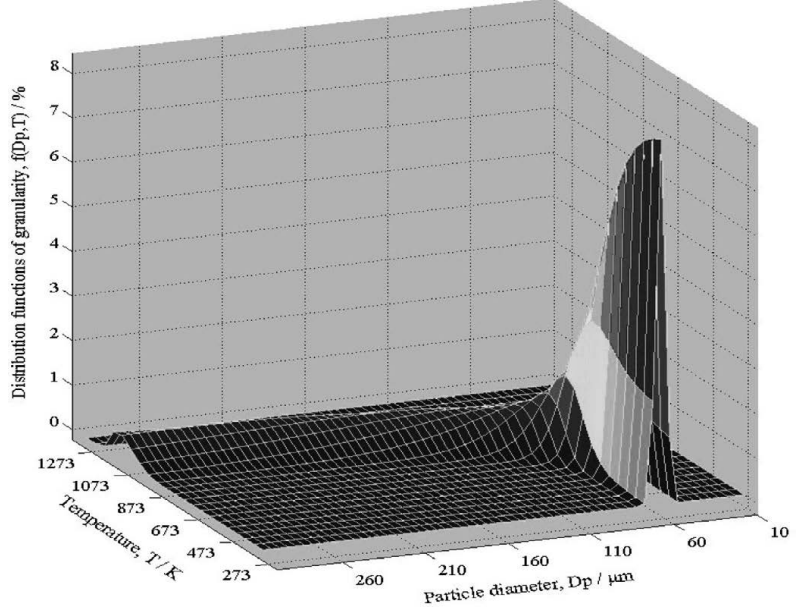

Fig. 6. Influence of temperature on logarithmic normal distribution and diameter of grains.
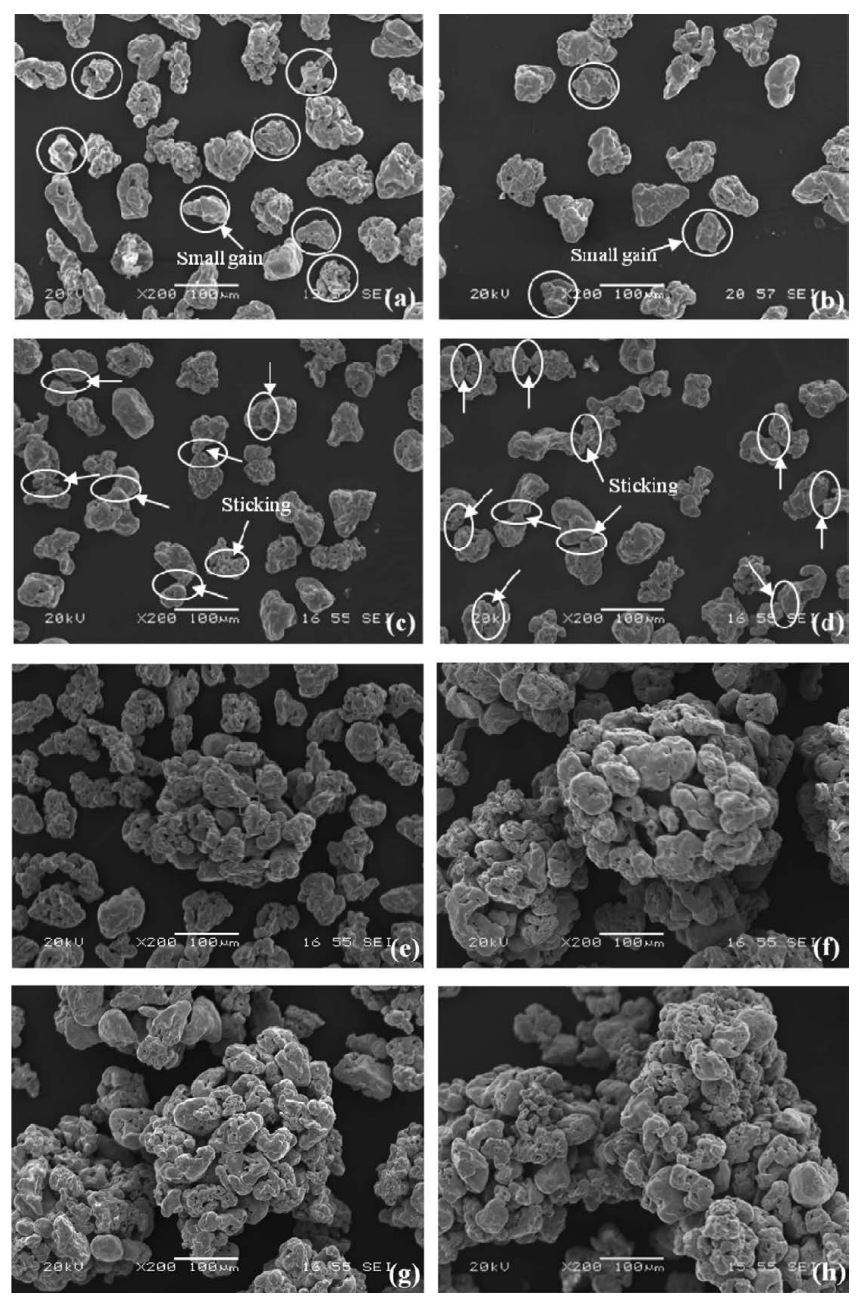

Fig. 7. SEM images of iron samples after fluidizing at different temperatures.

current operating condition is from $923 \mathrm{~K}$ to $973 \mathrm{~K}$, as shown in Fig. 3.

\subsection{Analysis of Sticking Reasons}

The surface morphology of sticking samples at $923 \mathrm{~K}$ and $1023 \mathrm{~K}$ are presented in Fig. 8. There does not exist obvious hooking whiskers at the surface of the iron particles, instead, what there exists are dense iron crystals. At the same time, 
there was no fresh precipitation iron at any temperature in inert atmosphere. Moreover, the DTA result of iron powder is shown in Fig. 9. With increasing temperature in the range from room temperature to $1073 \mathrm{~K}$, the DTA curve is a reposeful straight line without endothermic peak or exothermic peak. The result shows that any liquid phase is not appear in iron powder sample from room temperature to $1073 \mathrm{~K}$.

Studies by McLean and Murty et al. ${ }^{14,15)}$ that most metals such as iron would have logarithmic creep under stress at the temperature $0.3 T_{\mathrm{m}}\left(T_{\mathrm{m}}=1536^{\circ} \mathrm{C}\right)$ which was far below its melting point as most metals, and it even showed the property similar to the liquid around $0.5 T_{\mathrm{m}}$. According to their conclusion, it can be found that the iron particles would become soft around the temperature $T_{\mathrm{s}}\left(0.3 T_{\mathrm{m}}, 461^{\circ} \mathrm{C}\right.$ or 734 $\mathrm{K})$, beginning to present some viscosity. When temperature reaches $T_{\mathrm{c}}$ (about $0.5 T_{\mathrm{m}}$ ), particles would soften seriously and agglomerate together under the forces such as the crash between particles and appear certain creep, which show higher degree of sphericility in the particle micro-morphology as shown in Figs. 7(f)-7(h). And the critical temperature $T_{\mathrm{c}}$ is influenced by the operating conditions and becomes higher because the needed viscosity force between particles increases with the increase of momentum of particles, according to the result about the sticking tendency of particles in fluidized bed suggested by Langston et al.. ${ }^{16)}$

Thus it can be concluded that whiskers and newly reduced iron are not the necessary conditions for sticking. Above sticking temperature $\left(T_{\mathrm{s}}\right)$, iron particles will stick each other as they become soft and have viscoelasticity solid which is caused by increasing ability activity of atomic lattice.

In addition, experimental results indirectly proved that the fundamental influence factors of sticking are temperature and the content of iron at the surface of particles during the

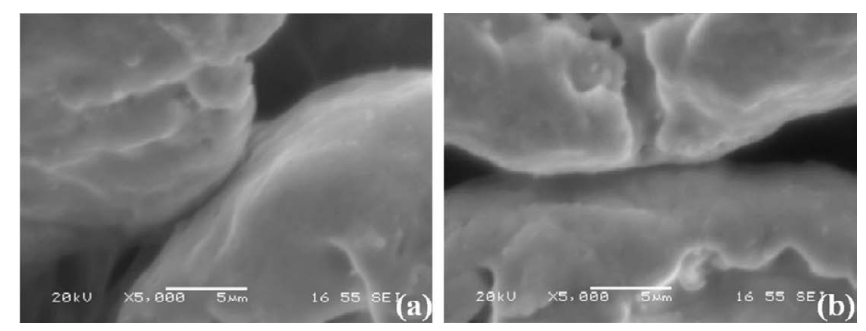

Fig. 8. Surface micromorphology of sticking samples.

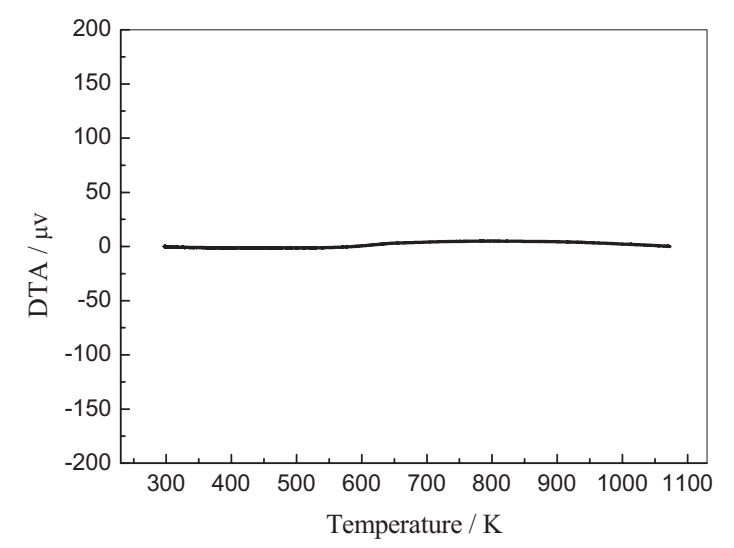

Fig. 9. DTA curve of iron powder. reduction of fine iron ore in fluidized bed. Under certain operating gas velocity, sticking appears as long as the accumulating iron amount at the surface is enough and temperature reaches critical temperature, $T_{\mathrm{c}}$.

\section{Conclusions}

The conclusions of this research can be summarized as follows:

(1) Iron powder after complete crystallization becomes viscous when temperature is between $673 \mathrm{~K}$ and $773 \mathrm{~K}$. Under current operating conditions, the critical temperature $\left(T_{\mathrm{c}}\right)$ of defluidization in fluidized bed was between $923 \mathrm{~K}$ and $973 \mathrm{~K}$.

(2) If operating temperature $(T)$ is lower than the starting temperature of sticking $\left(T_{\mathrm{s}}\right)$, pressure drop of fluidized bed is constant. When $T$ is higher than the critical temperature $\left(T_{\mathrm{c}}\right)$, pressure drop decreases suddenly and defluidization occurs. While $T$ is between $T_{\mathrm{s}}$ and $T_{\mathrm{c}}$, pressure drop decreases slowly, but it can still maintain fluidizing.

(3) Diameter of iron powder after agglomeration increases exponentially with increase of the temperature. Approximately, the transition temperature of diameter increasing is $923 \mathrm{~K}$. Diameter of iron powder increases slowly below $923 \mathrm{~K}$, while it increases rapidly above 923 K. Log-normal distribution function $f\left(D_{\mathrm{p}}, T\right)$ can be obtained by the statistics of granular size variation between $298 \mathrm{~K}$ and $1023 \mathrm{~K}$.

(4) Sticking and defluidization of iron powder in fluidized bed results from change of physical property of iron over a certain temperature. Whisker and incomplete crystallization are not necessary conditions for that.

\section{Acknowledgement}

This work is supported by the Natural Science Foundation of China and Baosteel under Grant No. 50834007. We would like to thank other member in our lab, for example C. Peng, Z. F. Cai, J.L. Meng and Q. H. Wang et al. for their encouragement and helpful comments.

\section{Nomenclature}

$D_{\mathrm{p}}$ : Particle diameter $[\mu \mathrm{m}]$

$D_{\mathrm{nL}}$ : Mean diameter $[\mu \mathrm{m}]$

$D_{50}$ : Corresponding grains size at $50 \%$ of grains cumulative distribution percent (median particle diameter) $[\mu \mathrm{m}]$

$D_{84.13}$ : Corresponding grains size at $84.13 \%$ of grains cumulative distribution percent $[\mu \mathrm{m}]$

$d_{\mathrm{i}}$ : Average grain size of No. $i$ particle size range $[\mu \mathrm{m}]$

$\left(\frac{-d \Delta p}{d t}\right)_{T}:$ Variation rate of the bed pressure drop over
time at $T$ temperature $[\mathrm{kPa} / \mathrm{min}]$

$n_{\mathrm{i}}$ : Sample number of the No. $i$ particle size range $[-]$

$\Delta p$ : Pressure drop of fluidized bed $[\mathrm{kPa}]$

$T$ : Temperature of fluidized bed $[\mathrm{K}]$

$T_{\mathrm{c}}$ : Critical temperature of defluidization $[\mathrm{K}]$

$T_{\mathrm{s}}$ : Start sticking temperature of iron powder [K] $t$ : ime [min]

$U\left(D_{\mathrm{p}}\right)_{T}$ : Fitting cumulative distribution functions of particle size at $T[\%]$ 
ISIJ International, Vol. 51 (2011), No. 8

\section{REFRENCES}

1) H. W. Gudenau, J. Fang, T. Hirata and U. Gebel: Steel Res., 60 (1989), 138.

2) J. H. Shao: Energy for Metall. Industry, 29 (2010), 18.

3) M. Komatina and H. W. Gudenau: Metalurgija-journal of Metallurgy, 10 (2004), 309.

4) J. Fang, S. J. Hao and Z. G. Li: Alternation Processes for Iron Production, Metallurgy Industry Press, Beijing, (2003), 20.

5) M. S. Guo, H. Z. Li and Y. C. Li: Handbook of fluidization, Chemical industry press, Beijing, (2008), 19

6) S. Hayashi and Y. Iguchi: ISIJ Int., 32 (1992), 962.
7) S. Hayashi, S. Sayama and Y. Iguchi: ISIJ Int., 30 (1990), 722.

8) R. Nicolle and A. Rist: Metall. Trans. B, 10B (1978), 429.

9) J. F. Gransden, J. S. Sheasby and M. A. Bergougnou: Chem. Eng. Prog. Symp. Ser., 66 (1970), 208.

10) J. F. Gransden and J. S. Sheasby: Can. Metall. Q., 13 (1974), 649

11) S. Hayashi and Y. Iguchi: ISIJ Int., 29 (1989), 596.

12) J. Fang: Iron and Steel., 26 (1991), 11

13) C. S. Zhang: Powder technology and equipment, East China university of science and technology press, Shanghai, (2007), 8.

14) D. McLean: Rep. Prog. Phys., 29 (1966), 1.

15) K. L. Murty, M. Gold and A. L. Ruoff: J. Appl. Phys., 41 (1970), 4917.

16) B. G. Langston and F. Stephens: J. Met., 12 (1960), 312. 